http://journal.unj.ac.id/unj/index.php/jpud

Volume 12 Edisi 2 November 2018

JURNAL PENDIDIKAN USIA DINI

DOI: https://doi.org/10.21009/JPUD.122

DOI: https://doi.org/10.21009/JPUD.122.10

\title{
PENINGKATAN KECERDASAN INTERPERSONAL MELALUI AKTIVITAS FISIK ANAK USIA 4-5 TAHUN
}

\author{
Nofi Marlina Siregar \\ Program Studi Pendidikan Olahraga, Universitas Negeri Jakarta \\ E-mail: Nofisiregar_fik96@yahoo.com
}

\begin{abstract}
ABSTRAK
Action research aims to improve interpersonal intelligence of children aged 4-5 years in Paud Ananda, South Jakarta. This research method uses the Action Research Method. The subjects in this study were children aged 4-5 years, totaling 15 children. This research was conducted for one month, this study consisted of two cycles and each cycle consisted of four meetings. In the first cycle there was an increase in good movement in children, but there were still children who had not yet completed the improvement in interpersonal intelligence with 9 children included in the criteria of less, 3 children included in the criteria of good, and 3 children included in the criteria enough. In the second cycle based on the results of the teacher and collaborator's assessment a maximum increase occurred or all children experienced an increase in interpersonal intelligence, the results of cycle 2 were declared successful. From this study it can be concluded that through physical activity in the form of a game model can improve interpersonal intelligence of children aged 4-5 years in Paud Ananda, South Jakarta.
\end{abstract}

Keywords: Interpersonal Intelligence, Physical Activity of Children Aged 4-5 Years

Penelitian Tindakan bertujuan untuk meningkatkan kecerdasan interpersonal anak usia 4-5 tahun di Paud Ananda Jakarta Selatan. Metode penelitian ini menggunakan Metode Penelitian Tindakan. Subjek dalam penelitian ini adalah anak-anak Paud berusia 4-5 tahun yang berjumlah 15 orang anak. Penelitian ini dilakukan selama satu bulan, penelitian ini terdiri dari dua siklus dan setiap siklus terdiri dari empat pertemuan. Pada siklus pertama terjadi peningkatan gerak yang baik pada anak-anak, namun masih ada anak yang belum tuntas dalam peningkatan kecerdasan interpersonalnya dengan jumlah 9 anak termasuk pada kriteria kurang, 3 anak termasuk pada kriteria baik, dan 3 anak termasuk pada kriteria cukup. Pada siklus kedua berdasarkan hasil penilaian guru dan kolaborator terjadi peningkatan yang maksimal atau semua anak mengalami peningkatan kecerdasan interpersonal, maka hasil dari siklus 2 dinyatakan berhasil. Dari penelitian ini dapat disimpulkan bahwa melalui aktifitas fisik berupa model permainan dapat meningkatkan kecerdasan interpersonal anak usia 4-5 tahun di Paud Ananda Jakarta Selatan

Kata Kunci: Kecerdasan Interpersonal, Aktifitas Fisik Anak Usia 4-5 Tahun

\section{PENDAHULUAN}

Selain kemampuan kognitif, tradisi teoritis terpisah telah menyarankan dimensi interpersonal, intrapersonal, dan intelektual, yang mencerminkan bagaimana anak-anak berhubungan dengan orang lain, mengelola tujuan dan bakat mereka sendiri, dan mengekpresikan berbagai ide masing-masing. Di tiga penelitian dengan prospektif longitudinal, Park 
dkk (2017) memeriksa struktur faktor karakter, asosiasi dengan kecerdasan dan ciri-ciri kepribadian dan validitas prediktif untuk hasil yang bersifat konsekuensi seperti hubungan teman sebaya, partisipasi kelas, dan nilai rapor.hasil penelitian menunjukkan bahwa karakter intelektual, interpersonal, dan intrapersonal yang terkait dengan keterbukaan terhadap pengalaman, keramahan, dan kesadaran setiap individu, hubungan teman sebaya positif paling konsisten diprediksi oleh karakter interpersonal, partisipasi kelas oleh karakter intelektual, dan nilai rapor oleh karakter intrapersonal. Secara kolektif, temuan penelitian mendukung karakter taksonomi tripartit dalam konteks sekolah.(Park, Tsukayama, Goodwin, Patrick, \& Duckworth, 2017).

Penelitian Tindakan ini bertujuan untuk meningkatkan kecerdasan interpersonal anak usia 4-5 tahun melalui aktivitas fisik, hal ini selaras dengan penelitian yang dilakukan oleh Mancini, Rigoli, Roberts, Heritage, \& Piek, (2018) mengenai hubungan antara keterampilan motorik dan faktor psikososial pada anak-anak. Penelitiannya memberikan dukungan untuk hubungan tidak langsung antara keterampilan motorik dan internalisasi masalah melalui masalah anak dengan teman sebaya pada anak usia dini, dan kompetensi fisik pada masa perkembangan anak. Penelitian ini dilakukan di Western Australia pada 12 lembaga pra-sekolah. Ini temuan penelitian juga menyoroti pentingnya intervensi psikomotor dengan target sesuai usia dalam intervensi psikomotor. Implikasi di masa depan diperlukan untuk lebih memahami bagaimana hubungan akitivitas fisik penghasil energi dan masalah-masalah internal dalam perspektif kecerdasan interpersonal dapat mempengaruhi tahapan perkembangan anak.

Penelitian Tindakan merupakan penelitian yang bertujuan untuk memberikan solusi terhadap masalah yang ada. (Wiriaatmadja, 2009) mengemukakan bahwa "penelitian tindakan adalah kajian sistematik dari upaya perbaikan pelaksanaan praktek pendidikan oleh sekelompok guru dengan melakukan tindakan-tindakan dalam pembelajaran, berdasarkan refleksi mereka mengenai hasil dari tindakan tersebut".

Metode-metode yang dapat meningkat kan kecerdasan anak sekarang sudah terlalu monoton dan cenderung tidak menarik bagi sang anak yang akan bertumbuh kembang. Aktivitas fisik bisa menjadi salah satu solusi dari masalah ini, karena anak cenderung lebih senang jika di berikan aktivitas fisik yang menarik bisa dalam bentuk permainan dan semacamnya. Bukan tidak mungkin jika dipadukan antara aktivitas fisik untuk anak yang bertujuan untuk meningkatkan kecerdasan interpersonal anak usia 4-5 tahun dapat memberikan solusi terbaik dari masalah ini. 
Peningkatan Kecerdasan Interpersonal... Nofi Marlina Siregar

Berdasarkan Penelitian terdahulu serta permasalahan terkait, maka penelitian tindakan ini bertujuan untuk meningkatkan kecerdasan interpersonal anak usia 4-5 tahun di Paud Ananda Jakarta Selatan melalui aktivitas fisik.

\section{KAJIAN TEORITIK}

\section{Kecerdasan Interpersonal}

Kecerdasan interpersonal adalah kemampuan menciptakan, membangun dan mempertahankan suatu hubungan antar pribadi (sosial) yang sehat dan saling menguntungkan. (Dewi, Kusmayadi, \& Usodo, 2014).

Kecerdasan interpersonal merupakan kecerdasan yang lebih unggul dari kecerdasan lainnya, kecerdasan interpersonal yang baik akan menuntun kita untuk dapat berfikir lebih keras menuju kesuksesan sedangkan kecerdasan interpersonal yang kurang baik akan membuat kita lebih mudah merasa frustasi. (Sholihah, Karyanto, \& Sugiharto, 2012).

Kecerdasan interpersonal memungkinkan kita untuk bisa memahami dan berkomunikasi dengan orang lain, melihat perbedaan dalam mood, tempramen, motivasi, dan kemampuan (Dewi et al., 2014).

Termasuk juga kemampuan untuk membentuk dan juga menjaga hubungan, serta mengetahui berbagai perasaan yang terdapat dalam suatu kelompok, baik sebagai anggota maupun sebagai pemimpin.
Adapun ciri-cirinya anak yang memiliki kecerdasan intrapersonal adalah: Memperlihatkan sikap lebih bebas dan memiliki kemauan yang lebih kuat dari anak lainnya, mengetahui kelemahan dan kelebihan dirinya sendiri dengan sadar dan realistis, mampu memberi reaksi lebih pada isu kontroversi, mampu secarra mandiri belajar dan bekerja, memiliki suatu pemikiran dan pandangan dari halayak umum, dapat menjadikan masa lalu sebagai pembelajaran, mampu mengekspresikan perasaannya dengan tepat, dapat mencapai suatu tujuan dengan lebih terarah (Adriany, 2011).

Berdasarkan teori diatas, yang dimaksud dengan kecerdasan intrapersonal atau kecerdasan diri adalah kemampuan yang dimilki seseorang untuk mampu melakukan (self selective), (self concept), kepekaan terhadap sesuatu dengan indikator melakukan kemampuan melihat diri sendiri, kemampuan memahami diri sendiri, kemampuan mengatur diri sendiri, mengevaluasi diri sendiri, sehingga anak dapat membangun hubungan baik secara pribadi.

\section{Aktifitas Fisik Anak Usia 4-5 Tahun}

Tubuh manusia merupakan suatu sistem yang kompleks dan sangatlah menarik. Seluruh organ yang ada pada tubuh manusia terbentuk pada masa prenatal atau saat dalam kandungan. (R Ariyana \& Rini, 2009) 
mengemukakan bahwa perkembangan fisik individu meliputi empat aspek, yaitu; System syaraf yang sangat mempengaruhi perkembangan kecerdasan dan emosi, otot-otot yang mempengaruhi perkembangan kekuatan dan kemampuan motorik, kelenjar endokrin, yang menyebabkan munculnya pola-pola tingkah laku baru, seperti pada remaja berkembang perasaan senang untuk aktif dalam suatu kegiatan yang sebagian anggotanya terdiri atas lawan jenis, struktur fisik/tubuh yang meliputi tinggi, berat dan proposi.

Perkembangan anak merupakan segala perubahan yang terjadi pada usia anak, yaitu pada masa:

1. Infancy toddlerhood (usia 0-3 tahun)

2. Early childhood (usia 3-6 tahun)

3. Middle childhood (usia 6-11 tahun)

Sedangkan perubahan yang terjadi pada diri anak tersebut meliputi perubahan pada aspek berikut:

1. Perkembangan Fisik

Pertumbuhan fisik adalah proses perubahan pada tubuh manusia yang meliputi peningkatan berat badan dan juga tinggi badan. Namun tak semua perkembangan berjalan seimbang, kebanyakan anak tumbuh dengan berat badan yang lebih besar dibanding dengan tinggi badan anak. Hal tersebut terjadi dikareakan meningkatnya ukuran sistem rangka, otot dan beberapa organ dalam tubuh lainnya.

2. Perkembangan Motorik

Perkembangan motorik adalah proses meningkatnya kemampuan gerak seseorang, gerakan-gerakan yang dilakukan anak merupakan hasil dari interaksi dari berbagai bagian dan sistem didalam tubuh yang dikontrol oleh otak.

\section{Kecerdasan Jamak}

Kecerdasan jamak merupakan sekumpulan dari kecerdasan yang dimiliki oleh setiap anak dalam fase awal dalam kehidupannya, kecerdasan jamak merupakan kecerdasan yang harus dikembangkan untuk menunjak kesuksesan seorang anak dimasa yang akan datang, karena kecerdasan jamak merupakan modal awal bagi seseorang untuk bisa meraih kesuksesan dalam hidupnya baik kehidupan sosial maupun kehidupan lainnya dan dirinya sendiri (Martani, 2012).

\section{METODOLOGI PENELITIAN}

Subjek penelitian dalam penelitian ini adalah anak usia $4-5$ tahun di Lembaga Pendidikan Anak Usia Dini ANANDA Jakarta Selatan yang berjumlah 15 orang. Metode penelitian ini metode yang digunakan adalah metode action research. Action Research adalah penelitian yang dilakukan dengan tujuan memperbaiki mutu praktik dalam pembelajaran. Sugiono menjelaskan bahwa penelitian tindakan merupakan 
Peningkatan Kecerdasan Interpersonal... Nofi Marlina Siregar

penelitian terapan yang fokus pada penelitian tertentu. (Sugiyono, 2016) Dalam perencanaan yang sesuai dengan prosedur penelitian tindakan yang dikemukakan oleh Kemmis dan Taggart, bahwa secara umum penelitian tindakan terdiri dari beberapa prosedur, yaitu: tahap perencanaan tindakan, tahap pelaksanaan tindakan, tahap pengamatan terhadap tindakan, tahap refleksi terhadap tindakan.

Metode penelitian ini berkembang bersama-sama antara peneliti dan kolabolator untuk menentukan kebijakan dalam setiap peningkatan aspek penerapan. (Zainuddin, Budiyono, 2014).

Perlakuan dalam penelitian
tindakan ini $\begin{array}{r}\text { adalah } \\ \text { dengan } \\ \text { menggunakan tindakan, dimana }\end{array}$
prograam perencanaan penerpan yang di implementasikan berupa kerangka pelaksanaan tindakan agar sesuai dengan kondisi peneliti. Desain dalam penelitian ini menggunakan desain penelitian tindakan dengan yang terdiri dari beberapa siklus dengan kerangka masing-masing siklus empat langkah dan pengulangan yang di mulai dari perencanaan (planing), tindakan (acting), pengamatan (observing), refleksi (reflecting), dan di lanjut dengan perencanaan kembali apabila pada siklus pertama belum tuntas dan memenuhi target penelitian.

\section{HASIL DAN PEMBAHASAN}

Action Research adalah penelitian yang dilakukan dengan tujuan memperbaiki mutu praktik dalam pembelajaran. Menurut Endang Mulyatiningsih berpendapat bahwa penelitian tindakan (action reasearch) termasuk dalam ruang lingkup penelitian terapan (applied research) yang menggabungkan antara pengetahuan, penelitian dan tindakan (Mulyatiningsih, 2011). Dalam perencanaan yang sesuai dengan prosedur penelitian tindakan yang dikemukakan oleh Kemmis dan Taggart, bahwa secara umum penelitian tindakan terdiri dari beberapa prosedur, yaitu: tahap perencanaan tindakan, tahap pelaksanaan tindakan, tahap pengamatan terhadap tindakan, tahap refleksi terhadap tindakan. (Robert, 1997).

Pembahasan yang mengenai penelitian ini yaitu seperti, Tes awal memiliki tujuan untuk mengetahui secara awal bagaimana kecerdasan interpersonal anak yang di fokuskan pada interaksi, toleransi, persepsi dan empati. Hal ini merupakan suatu keharusan untuk mengetahui standar awal kecerdasan interpersonal yang harus diketahui oleh peneliti dan kolaborator agar dapat menentukan penerapan aktifitas fisik yang sesuai.

Subjek dalam penelitian ini adalah anak-anak Paud berusia 4-5 tahun yang berjumlah 15 orang anak. Penelitian ini dilakukan selama satu bulan. 


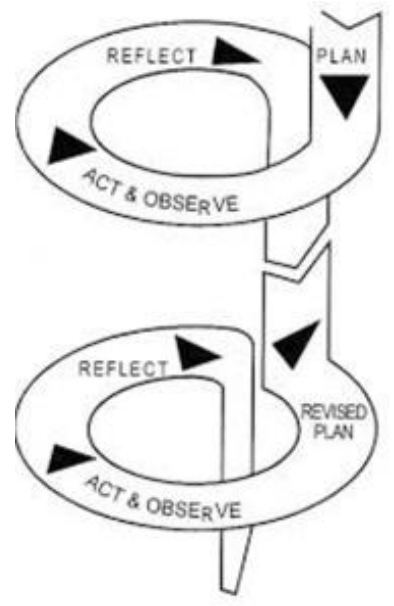

Gambar 1. Siklus Penelitian Tindakan Kelas

Tabel 1. Hasil Asismen Awal Kecerdasan Interpersonal

\begin{tabular}{|c|c|c|c|c|c|c|}
\hline \multirow{2}{*}{ No } & \multirow{2}{*}{ Nama } & \multicolumn{4}{|c|}{ Indikator } & \multirow[t]{2}{*}{$\mathrm{N}$} \\
\hline & & Interahsi & Toleransi & Persepsi & Empati & \\
\hline 1 & Arya & 77.8 & 66.7 & 66.7 & 66.7 & 7 \\
\hline 2 & Biyan & 44.4 & 55.6 & 50 & 50 & 5 \\
\hline 3 & Devi & 55.6 & 44.4 & 50 & 50 & 5 \\
\hline 4 & Efli & 44.4 & 44.4 & 50 & 50 & 4 \\
\hline 5 & Fathir & 88.9 & 88.9 & 100 & 66.7 & 8 \\
\hline 6 & Fatih & 55.6 & 55.6 & 66.7 & 50 & 5 \\
\hline 7 & Habibah & 100 & 88.9 & 83.3 & 66.7 & 8 \\
\hline 8 & Hendra & 66.7 & 44.4 & 50 & 50 & 5 \\
\hline 9 & Iqgbal & 66.7 & 66.7 & 66.7 & 66.7 & 7 \\
\hline 10 & Lala & 55.6 & 33.3 & 50 & 33.3 & 4 \\
\hline 11 & Lili & 33.3 & 44.4 & 33.3 & 33.3 & 3 \\
\hline 12 & Nadini & 33.3 & 44.4 & 50 & 66.7 & 4 \\
\hline 13 & Nazwa & 44.4 & 44.4 & 50 & 50 & 4 \\
\hline 14 & Salwa & 77.8 & 66.7 & 66.7 & 66.7 & 7 \\
\hline 15 & Tasya & 100 & 77.8 & 100 & 100 & 9 \\
\hline
\end{tabular}

2. Nilai $>70$ termasuk pada kriteria Cukup

3. Nilai $>60$ termasuk pada kriteria Kurang

Berdasarkan asismen awal indikator kecerdasan interpersonal anak memiliki hasil 9 anak termasuk dalam kriteria kurang, 3 orang anak termasuk pada kriteri baik, dan 3 anak termasuk pada kriteria cukup. Agar lebih jelas dapat dilihat pada diagram pie berikut.

HASIL TES AWAL KECERDASAN INTERPERSONAL ANAK USIA DINI

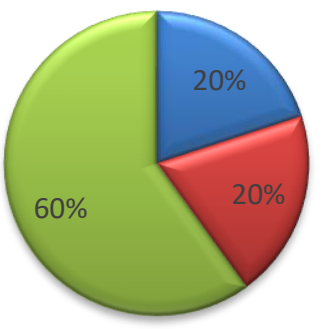

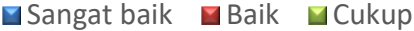

Gambar 2. Diagram pie hasil awal kecerdasan interpersonal

\section{Hasil Penelitian Siklus 1}

Setelah kegiatan penerapan aktifitas fisik berupa model permainan untuk meningkatkan kecerdasan interpersonal anak usia 4-5 tahun di PAUD ANANDA, maka diperoleh hasil pengamatan sebagai berikut:

Keterangan :

1. Nilai $>80$ termasuk pada kriteria Baik 
Peningkatan Kecerdasan Interpersonal... Nofi Marlina Siregar

Tabel 2. Hasil Pengamatan Siklus 1 Indikator Kecerdasan Interpersonal

\begin{tabular}{ccccccc}
\hline & & \multicolumn{4}{c}{ Indikator } & Nilai \\
\cline { 3 - 7 } No & Nama & Interaksi & Toleransi & Persepsi & Empati & Rata-rata \\
\hline 1 & Arya & 88.9 & 77.8 & 66.7 & 66.7 & 70.0 \\
2 & Biyan & 55.6 & 55.6 & 66.7 & 50 & 57.0 \\
3 & Devi & 66.7 & 44.4 & 50 & 50 & 52.8 \\
4 & Erli & 55.6 & 55.6 & 66.7 & 50 & 57.0 \\
5 & Fathir & 100.0 & 88.9 & 100 & 83.3 & 93.1 \\
6 & Fatih & 66.7 & 55.6 & 66.7 & 50 & 59.8 \\
7 & Habibah & 100 & 100 & 83.3 & 66.7 & 87.5 \\
8 & Hendra & 66.7 & 44.4 & 50 & 50 & 52.8 \\
9 & Iqbal & 88.9 & 77.8 & 66.7 & 66.7 & 70.0 \\
10 & Lala & 55.6 & 33.3 & 50 & 33.3 & 43.1 \\
11 & Lili & 33.3 & 44.4 & 33.3 & 33.3 & 36.1 \\
12 & Nadini & 55.6 & 44.4 & 50 & 66.7 & 54.2 \\
13 & Nazwa & 44.4 & 55.6 & 50 & 50 & 50.0 \\
14 & Salwa & 77.8 & 77.8 & 66.7 & 66.7 & 70.0 \\
15 & Tasya & 100 & 100 & 100 & 100 & 100 \\
\hline
\end{tabular}

Keterangan:

1. Nilai $>80$ termasuk pada kriteria Baik

2. Nilai $>70$ termasuk pada kriteria Cukup

3. Nilai > 60 termasuk pada kriteria Kurang

Setelah penerpan siklus 1 ddilakukan dan diamati berdasarkan data di atas maka dapat di simpulkan sebanyak 9 anak termasuk pada kriteria kurang, 3 anak dalam kriteria baik, dan 3 anak dalam kriteria cukup. Agar dapat lebih jelas maka dapat di lihat pada diagram pie berikut;

\section{HASIL PENELITIAN \\ SIKLUS 1}

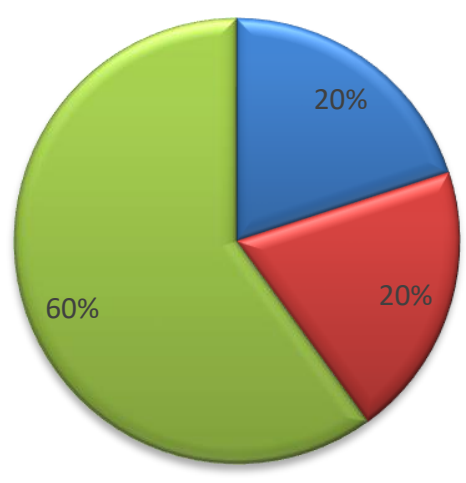

घBaik घCukup $\square$ Kurang

Gambar 3. Diagram pie hasil penelitian siklus 1 kecerdasan interpersonal

\section{Hasil Penelitian Siklus 2}

Setelah dilakukan refleksi pada siklus 1 ternyata hasilnya belum mencpai standar yang telah di sepakati oleh peneliti dan kolaborator, atau sama sekali belum ada peningkatan sehingga siklus kembali di lanjutkan. Setelah di lakukan penerapan aktifitas fisik maka diperoleh hasil sebagai berikut: 
Tabel 3. Hasil Pengamatan Siklus 2 Indikator Kecerdasan Interpersonal

\begin{tabular}{ccccccc}
\hline & & \multicolumn{2}{c}{ Indikator } & & Nilai \\
\cline { 3 - 7 } No & Nama & Interaksi & Toleransi & Persepsi & Empati & rata \\
\hline 1 & Arya & 100 & 89 & 100 & 83 & 93 \\
2 & Biyan & 67 & 89 & 100 & 100 & 89 \\
3 & Devi & 67 & 67 & 83 & 100 & 79 \\
4 & Erli & 89 & 78 & 100 & 100 & 92 \\
5 & Fathir & 100 & 100 & 100 & 100 & 100 \\
6 & Fatih & 78 & 100 & 100 & 100 & 95 \\
7 & Habibah & 100 & 100 & 100 & 100 & 100 \\
8 & Hendra & 89 & 78 & 100 & 100 & 92 \\
9 & Iqbal & 100 & 89 & 100 & 100 & 97 \\
10 & Lala & 67 & 89 & 83 & 100 & 85 \\
11 & Lili & 67 & 67 & 100 & 100 & 84 \\
12 & Nadini & 89 & 78 & 100 & 100 & 92 \\
13 & Nazwa & 78 & 89 & 83 & 100 & 88 \\
14 & Salwa & 100 & 89 & 100 & 100 & 97 \\
\hline
\end{tabular}

Keterangan:

1. Nilai $>80$ termasuk pada kriteria Baik

2. Nilai $>70$ termasuk pada kriteria Cukup

3. Nilai > 60 termasuk pada kriteria Kurang

Berdasarkan data pengamatan siklus 2 maka diperoleh data sebanyak 14 orang anak termasuk pada kriteria baik, 1 anak termasuk pada kriteria cukup dan tidak ada lagi anak dalam kategori kurang, untuk lebih jelas dapat dilihat pada diagram pie berikut.
SIKLUS 2 KECERDASAN

INTERPERSONAL

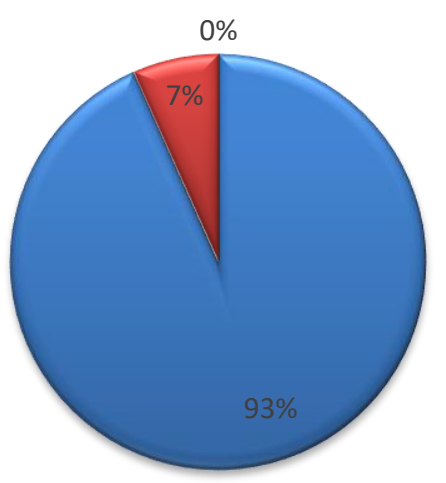

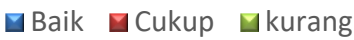

Gambar 4. Diagram pie hasil penelitian siklus 2 kecerdasan interpersonal

\section{KESIMPULAN, IMPLIKASI DAN SARAN}

Berdasarkan data yang telah di peroleh oleh peneliti dan kolaborator, maka dapat disimpulkan bahwa melalui aktivitas fisik berupa model permainan bisa permainan bola kecil, bola besar, permainan tradisonal, dan modifikasi permainan yang lebih menarik dan kreatif dapat meningkatkan kecerdasan interpersonal anak usia 4-5 tahun di PAUD ANANDA Jakarta Selatan.

Penerapan aktivitas fisik berupa model permainan pada anak usia 4-5 tahun bukanlah hal yang mudah apalagi untuk menyampaikan maksud pada anak yakni upaya peningkatan kecerdasan interpersonal pada anak, hal demikian haruslah di dukung dengan pendekatan khusus pada anak dan aktivitas fisik yang diberikan haruslah bervariasi dan menarik. 
Peningkatan Kecerdasan Interpersonal... Nofi Marlina Siregar

Peningkatan kecerdasan interoersonal yang ditingkatkan melalui aktivitas fisik pada dasarnya mengacu pada kemampuan anak berinteraksi, menyampaikan persepsi, memiliki toleransi dan dapat memiliki rasa empati dengan baik.

Penerapan aktivitas fisik berupa model permainan dapat meningkatkan aspek interaksi pada anak sebanyak $16 \%$, toleransi $23 \%$, persepsi $33 \%$ m dan empati sebanyak 93\%. Hal demikian menjadi perhatian bagi peneliti untuk memberi masukan kepada para guru agar senantiasa memiliki pemikiran yang lebih kreatif dan inovatif dalam mengajar agar anak dapat memahami dan mengembangkan kecerdasan interpersonalnya.

Pemberian aktivitas fisik ini dapat diterapkan menggunakan alat maupun tidak, dapat dilakukan di luar maupun di dalam kelas. Selain dapat meningkatkan kecerdasan interpersonal anak, penerapan aktivitas fisik ini juga mampu meningkatkan konsentrasi anak yang cenderung lebih singkat dan mudah jenuh. Selain itu anak juga memiliki motivasi lebih untuk belajar dengan cara yang menyenangkan.

\section{DAFTAR PUSTAKA}

Adriany, V. (2011). Optmalisasi Perkembangan Anak Usia Dini Melalui Kegiatan Penyuluhan Deteksi Dini Tumbuh Kembang Anak. Retrieved from http://jurnal.upi.edu/file/Vina.pdf

Dewi, A. P., Kusmayadi, T. A., \& Usodo,
B. (2014). Eksperimentasi Model Numbered Heads Together dengan Make A Match (NHT MM) dan Numbered Heads Together dengan Bamboo Dancing (NHT BD) Ditinjau dari Kecerdasan Interpersonal. Jurnal Elektronik Pembelajaran Matematika, 2(2), 193-201.

Mancini, V. O., Rigoli, D., Roberts, L. D., Heritage, B., \& Piek, J. P. (2018). The relationship between motor skills and psychosocial factors in young children: A test of the elaborated environmental stress hypothesis. British Journal of Educational Psychology, 88(3), 363-379.

https://doi.org/10.1111/bjep.12187

Martani, W. (2012). Metode Stimulasi dan Perkembangan Emosi Anak Usia Dini. Jurnal Psikologi, 39(1), 112-120.

Mulyatiningsih, E. (2011). Metode Penelitian Terapan Bidang Pendidikan. Bandung: Alfabeta.

Park, D., Tsukayama, E., Goodwin, G. P., Patrick, S., \& Duckworth, A. L. (2017). A tripartite taxonomy of character: Evidence for intrapersonal, interpersonal, and intellectual competencies in children. Contemporary Educational Psychology, 48, 1627.

https://doi.org/10.1016/j.cedpsych. 2016.08.001

R Ariyana, D., \& Rini, N. S. (2009). Hubungan pengetahuan ibu tentang perkembangan anak dengan perkembangan motorik kasar dan motorik halus anak usia 4-5 tahun Di TK Aisyiyah Bustanul Athfal 7 Semarang. Jurnal Keperawatan (FIKkes), 2(2), 11-20. 
Robert, S. F. (1997). Essential of Understanding Psychology. New York: McGraw-Hill Companies, Inc.

Sholihah, I. M., Karyanto, P., \& Sugiharto, B. (2012). Kekuatan Dan Arah Kemampuan Metakognisi, Kecerdasan Verbal, Dan Kecerdasan Interpersonal Hubungannya Dengan Hasil Belajar Biologi Siswa Kelas Xi Ipa Sma Negeri 3 Sukoharjo Strenght and Direction of Metakognitif Awareness, Verbal Intellegences, and Interpe. Pendidikan Biologi Januari, 4(1), 31-39.

Sugiyono. (2016). Skripsi, Tesis dan Disertasi. Bandung: Alfabeta.

Wiriaatmadja, R. (2009). Metode Penelitian Tindakan Kelas. Bandung: Remaja Rosdakarya.

Zainuddin, Budiyono, I. S. (2014). Eksperimentasi Model Pembelajaran Kooperatif Tipe Two Numbered dan Numbered Heads Together Pada Materi Pokok Fungsi DItinjau dari Kecerdasan Interpersonal Siswa kelas VIII SMPN Se-kota Surakarta. Jurnal Elektronik Pembelajaran Matematika, 2(2), 121-130. 